\title{
Pre-feasibility study of a grid connected wind-PV hybrid system with energy storage and power prediction
}

\author{
Hans Bludszuweit, José Antonio Domínguez and José Luis Bernal \\ Department of Electrical Engineering \\ University of Zaragoza \\ C / María de Luna 3, 50018 Zaragoza (Spain) \\ phone:+34 97676 2404, fax: + 3497676 2226, e-mail: hblud@unizar.es, jadona@unizar.es, jlbernal@unizar.es
}

\begin{abstract}
A simulation system using Matlab/ Simulink ${ }^{\circledR}$ for battery sizing in grid-connected renewable generation is compared with results from the optimization tool HOMER. The system is intended to reinforce remote weak distribution grids. The power injection of the hybrid generation system to the grid is defined by a power prediction method. The battery smoothes the power output and absorbs the prediction errors. As a reference, a wind - battery system is chosen. The impact of the integration of photovoltaic generation is studied. As an example for the meteorological conditions, wind data from the airport and solar irradiation mean values for Zaragoza are applied. Simulated renewable power ranges from $600 \mathrm{~kW}$ to 1.1 MW. The battery sizes obtained from the Matlab simulation differ substantially from HOMER results but show similarities. This is due to the difference in the battery models. Integration of solar generation can reduce battery size relative to total installed power and also reduce total cost of generated energy.
\end{abstract}

Key words: Hybrid, distributed generation, storage, wind-pv-battery-system

\section{Introduction}

In the past, renewable energy generation only was considered in two main applications. The first was to create stand alone systems for remote places where no connection to the power grid is available. The second application which is very important is the injection of the energy into the grid. In this case, strong grid conditions are needed if renewable energy is fed into the grid without any stability control. This is justified for renewable penetration levels up to $5 \%$ [1] of the short circuit power of the grid. If the generated power exceeds this level, the grid can be considered as weak relative to the renewable power generation and additional efforts are needed to guarantee the grid stability. If the injection of energy takes place directly in the distribution grid at low voltages, this level of penetration can be reached very quickly. Therefore, if high penetration levels (up to $100 \%$ are desired, the renewable or distributed generation has to assume stability control tasks. Modern power electronic devices make possible a reactive power control.

The scope of this work concentrates on the sizing of the elements of a hybrid renewable energy system which is able to provide in principal a constant power output. If this is achieved, the output easily can be adapted to the consumption needs. But at a first step a constant power output is assumed to have a first guess for the prefeasibility study. The simulations in HOMER are carried out without grid connection because the grid is assumed to be very weak and as a first approach, no energy might be absorbed by the system. In a more advanced stage of the study the possibility of energy absorption will be crucial for the desired functionality of this system as a grid stabilizing unit.

In the literature very little examples can be found where renewable energy sources are used to stabilize a weak distribution grid but some promising studies have been done for island grids. Projects are under development in Greece [2], Portugal [3] and the Canary Islands [4].

\section{Definitions}

\section{A. Important Indicators}

In this paragraph the definitions for some important system performance indicators are given mainly according to the HOMER help.

The levelized cost of energy COE is the most important optimization parameter in HOMER. It reflects the average cost of producing electricity. HOMER calculates the COE using the following formula: 


$$
C O E=\frac{C_{\text {ann,tot }}}{E_{\text {served }}}
$$

where

COE : Levelized cost of energy [\$/(kWh a)]

$C_{a n n, t o t}$ : Total annualized cost of the system [\$/a]

$E_{\text {served }}:$ Served energy $[\mathrm{kWh} / \mathrm{a}]$

The battery throughput $\boldsymbol{Q}_{\boldsymbol{B} \text { at }}$ is the amount of energy which cycles through the battery bank in one year. Throughput is defined as the change in energy level of the battery bank, measured after charging losses and before discharging losses. It can be expressed as a relative number $\boldsymbol{q}_{\text {Bat }}$ by dividing it by the total generated energy $\boldsymbol{E}_{\text {total }}$ :

$$
q_{\text {Bat }}=\frac{Q_{\text {Bat }}}{E_{\text {total }}}
$$

where

$$
\begin{array}{ll}
q_{\text {Bat }} & : \text { Relative battery throughput } \\
Q_{\text {Bat }} & : \text { Battery throughput [MWh/a] which cycles } \\
& \text { through the battery bank in one year } \\
E_{\text {total }}: \text { Total generated energy per year [MWh/a] }
\end{array}
$$

The storage loss factor SLF is defined as the total energy loss originated by battery charging/discharging and the back to back converter and can be calculated as follows:

$$
S L F=1-q_{\text {Bat }}\left(1-\eta_{\text {Bat }} \cdot \eta_{\text {Conv }}\right)
$$

where

$$
\begin{array}{ll}
S L F & : \text { Storage loss factor } \\
q_{\text {Bat }} & : \text { Relative battery throughput } \\
\eta_{\text {Bat }} & : \text { Round trip efficiency of the battery } \\
\eta_{\text {Conv }} & : \text { Round trip efficiency of the converter }
\end{array}
$$

The capacity factor $\boldsymbol{C F}$ used in energy generation units and describes the availability of the generating unit. It is calculated by the quotient of the generated energy per year $E_{\text {total }}$ and the energy that would have been generated if the unit run all the year at nominal power $P_{\text {nom }}$. This energy is calculated by the product of nominal power and the hours of the year $(8760 \mathrm{~h})$ :

$$
C F=\frac{E_{\text {total }}}{P_{\text {nom }} \cdot 8760 h}
$$

where

$C F \quad$ : Capacity factor

$E_{\text {total }}$ : Total generated energy per year [MWh/a]

$P_{\text {nom }}:$ Nominal power $[\mathrm{MW}]$ of the generator

The system capacity factor $\boldsymbol{C F}_{\text {sys }}$ is the CF of the wind turbine multiplied by the storage loss factor $S L F$.

$$
C F_{s y s}=C F \cdot S L F
$$

where

$$
\begin{array}{ll}
C F_{\text {sys }} & : \text { System capacity factor } \\
C F & : \text { Capacity factor } \\
S L F & : \text { Storage loss factor }
\end{array}
$$

Excess energy $\boldsymbol{E}_{\text {excess }}$ (or excess electricity) is surplus electrical energy that must be dumped because it cannot be used to serve a load or charge the batteries. An isolated system always will produce more energy than needed if a high availability is desired. The excess electricity is given in $\mathrm{kWh}$ per year in the HOMER results window. In this case it is also interpreted as negative prediction error (prediction is lower than generation).

Unmet load $\boldsymbol{E}_{\text {unmet }}$ is electrical load (or demand) that the power system is unable to serve. In isolated systems it might be too expensive to cover $100 \%$ of the yearly demand. Therefore HOMER permits the definition of a maximum unmet load per year in percent. In the simulation results the actual unmet load is given in percent and in $\mathrm{kWh}$. In this case it is also interpreted as positive prediction error (prediction is higher than generation).

A capacity shortage is a shortfall that occurs between the required operating capacity and the actual amount of operating capacity the system can provide. The required operating capacity is the sum of the operating reserve and the load.

The operating reserve provides a margin to account for intra-hour deviations from the hourly average of the load or the renewable power output. The default value is $10 \%$ but in the presented simulations, operation reserve is set to zero. In this case unmet load and capacity shortage are almost the same.

The prediction error $\boldsymbol{P E}$ is defined as follows:

$$
P E=\frac{E_{\text {unmet }}+E_{\text {excess }}}{E_{\text {demand }}}
$$

where

$$
\begin{array}{ll}
P E & : \text { Prediction Error } \\
E_{\text {unmet }}: \text { Unmet load [MWh/a] } & : \text { Excess Energy [MWh/a] } \\
E_{\text {excess }}: \text { Exces } & E_{\text {demand }}: \text { Total annual energy demand [MWh/a] }
\end{array}
$$

\section{B. Renewable resources}

\section{Wind energy:}

Wind data is taken from the Wind Atlas of Aragon (“Atlas eólico de Aragón”) [9]. Two sites are considered: Zaragoza Airport and La Muela. From Zaragoza Airport monthly mean values are given and a reasonable correlation with all other sites is demonstrated in the Wind Atlas. Therefore the monthly mean values from the airport site ( $4.6 \mathrm{~m} / \mathrm{s}$ yearly mean) are scaled to $5.7 \mathrm{~m} / \mathrm{s}$ to obtain the monthly values for La Muela site which represents the most favourable wind resource in Aragon. The well known formula for the wind power is:

$$
P_{\text {wind }}=\frac{1}{2} \rho \cdot A \cdot v_{\text {wind }}^{3}
$$

where

$$
\begin{array}{ll}
P_{\text {wind }} & : \text { Wind power }[\mathrm{W}] \\
\rho & : \text { Air density }\left[\mathrm{kg} / \mathrm{m}^{3}\right] \\
A & : \text { Rotor area }\left[\mathrm{m}^{2}\right] \\
v_{\text {wind }} & : \text { Wind speed }[\mathrm{m} / \mathrm{s}]
\end{array}
$$

\section{Solar energy}

Solar radiation data is taken from the Solar Radiation Atlas of Aragon (“Atlas de radiación solar en Aragón”) 
[10]. Monthly means are given for a $30^{\circ}$ inclination. The yearly radiation for Zaragoza sums up to 1649 $\mathrm{kWh} /\left(\mathrm{m}^{2} \mathrm{a}\right)$.

\section{A simple prediction method: Persistence}

In order to reduce the needed storage capacity a simple power prediction method is chosen. In consequence power output is variable and storage is only needed to guarantee the predicted values compensating the prediction error. Depending on the prediction method power output levelling can be achieved as a secondary benefit.

The prediction method is based on the persistence approach. This means that within a given time interval the prediction is equal to the mean value of the last time interval. But in this case, a modification was applied to achieve a kind of "best case" prediction. It is assumed that the mean generation is known exactly and so the prediction is equal to the mean generated power in the same time interval. The prediction is therefore a step function for the injected power (or the AC-load, modelled in HOMER) with constant power during the prediction interval. This time interval can reach from several hours up to half a year. In this meaning, the constant load is a special case of one year prediction interval. The step function is obtained from the hourly WECS power output data provided by HOMER. This approach makes it possible to compare the results with the findings in [11] where several prediction methods were compared.

\section{Description of the system}

\section{A. Reference system}

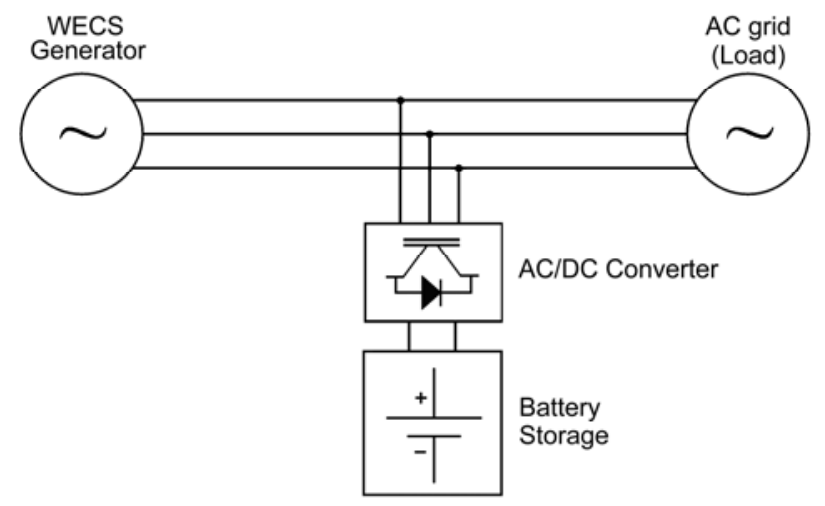

Fig. 1. Reference system configuration

As a reference system a wind generator (WECS) is directly connected to the grid and is equipped with a battery bank (see figure 1). The system elements are listed in table I.

The simulation in HOMER is done without grid connection to find out the optimum battery size. Power injection to the grid is simulated by an AC-load. As a first approach, constant power injection and therefore a constant load is assumed. Then a simple prediction method is adopted which results in a variable load.
Battery sizing results are compared with the findings in [11].

TABLE I. - Elements of the reference system.

\begin{tabular}{|c|c|}
\hline System Element & Characteristic \\
\hline Wind resource (yearly mean) & 4.6 or $5.7 \mathrm{~m} / \mathrm{s}$ \\
\hline Solar resource & $1649 \mathrm{kWh} /\left(\mathrm{m}^{2} \mathrm{a}\right)$ \\
\hline Wind Turbine $^{1}$ & $600 \mathrm{~kW}$ \\
\hline Lead Acid Battery cell $^{2}$ & $2 \mathrm{~V} / 3000 \mathrm{Ah}$ \\
\hline Round trip efficiency $\eta_{B a t}$ & $80 \%$ \\
\hline Converter efficiency $\eta_{\text {Conv }}$ & $81 \%$ \\
\hline
\end{tabular}

\section{B. Wind $-P V-$ battery system}

A very important improvement in terms of reduced storage capacity is expected when solar energy is introduced to the system. At the one hand solar resources in Zaragoza are quite high and on the other hand solar energy do not fluctuate as rapidly as the wind speed. The same prediction method can be applied as in the pure wind - battery system.

Three cases were considered: PV-only with $600 \mathrm{~kW}$ installed power, wind $600 \mathrm{~kW}$ plus PV $300 \mathrm{~kW}$ and wind $600 \mathrm{~kW}$ plus PV $300 \mathrm{~kW}$. Because only one wind generator with $600 \mathrm{~kW}$ is considered, no variation in wind power is possible.

\section{Simulation results}

\section{A. Reference system}

\section{A.1. Constant load determination}

The reference system was simulated in two scenarios:

1) A: $4.6 \mathrm{~m} / \mathrm{s}$ mean wind speed (Zaragoza airport)

2) B: $5.7 \mathrm{~m} / \mathrm{s}$ mean wind speed (La Muela)

Simulations revealed a low capacity factor (CF) for the wind turbine of about $13.3 \%$ in scenario A, generating $700 \mathrm{MWh} / \mathrm{a}$. This might be due to the power curve of the wind turbine which is not optimized for low wind speeds. But for the latter comparison with results from [11] where $144 \mathrm{~h}$ of real wind data is used, this value is more adequate. In [11] CF reaches only $11.9 \%$.

The higher mean wind speed in scenario B in turn leads to an excellent CF of over $24.5 \%$ which is equal to a generation of $1286 \mathrm{MWh} / \mathrm{a}$. The difference of only 1.1 $\mathrm{m} / \mathrm{s}$ mean wind speed almost doubles the generated power output. Here it can be appreciated the fact that the wind power is proportional to the third power of the wind speed. 
The constant load is calculated depending on the expected mean power output of the wind turbine. As a first guess the constant load can be calculated as the product of the nominal power of the wind turbine and the system capacity factor $C F_{\text {sys. }}$. Due to the important battery throughput $q_{\text {Bat }}$ (69\% in case A and $53 \%$ in scenario B), the storage loss factor SLF cannot be neglected. Using the efficiencies given in table I, SLF in case A is 0.758 and 0.814 in case $\mathrm{B}$. This leads to a theoretical mean power of $61 \mathrm{~kW}$ in case $\mathrm{A}$ and $120 \mathrm{~kW}$ in case $\mathrm{B}$. Simulation results showed quite good accordance with mean powers of $63 / 116 \mathrm{~kW}$ for the two cases respectively.

System losses, battery throughput and constant load power depend on each other. If system losses are high, a lower mean power can be supplied. But system losses depend on battery size and throughput which in turn depends on the relation between load and generated power. Thus, the constant power output of the system had to be determined iteratively. In this procedure, excess energy and unmet load had to be minimized because both represent the deviation from the predicted constant power output and can be termed as "prediction error". In this study a prediction error of $3 \%$ is considered acceptable (see definition in chapter 2). The results of the iterative determination of the constant load along with the most important system parameters are given in table II. The unmet and excess energy are included in the storage loss factor (SLF) because both are due to the incapacity of the battery to serve charge or discharge demand. Therefore, SLF is equal to the system efficiency.

TABLE II. - Simulation results of the reference system with constant output power $\mathrm{P}$ for two mean wind speeds: case A: $4.6 \mathrm{~m} / \mathrm{s}$, case B: $5.7 \mathrm{~m} / \mathrm{s}$.

\begin{tabular}{cccccccc}
\hline & $\begin{array}{c}\mathbf{q}_{\mathrm{Bat}} \\
\text { [\%] }\end{array}$ & $\begin{array}{c}\text { SLF } \\
\text { [\%] }\end{array}$ & $\begin{array}{c}\text { unmet } \\
\text { [\%] }\end{array}$ & $\begin{array}{c}\text { excess } \\
{[\%]}\end{array}$ & $\begin{array}{c}\text { battery } \\
\text { [MWh] }\end{array}$ & $\begin{array}{c}\text { COE } \\
{[\mathbf{\$} / \mathbf{k W h}]}\end{array}$ & $\begin{array}{c}\mathbf{P} \\
{[\mathbf{k W}]}\end{array}$ \\
\hline A & 67.8 & 78.4 & 2.2 & 0.8 & 193.8 & 4.90 & 63 \\
B & 52.9 & 78.8 & 2.9 & 3.1 & 196.5 & $\mathbf{2 . 9 6}$ & 116 \\
\hline
\end{tabular}

\section{A.2. Reference system with simple prediction}

In this configuration, the load is variable according to the prediction time interval (see paragraph 3.2.1). From the simulation results in the previous section, hourly wind generation data is available. This time series is used to generate step functions with the following time intervals: 1, 3, 6, 12, 24 hours, 2, 7, 30 days and 6 months. The predicted value at each step is the mean power of this time interval. The annual mean value stays unchanged and corresponds to the WECS production without storage losses. To convert this production profile into a load profile, system losses must be included. HOMER permits the setting of a scaled annual average consumption $[\mathrm{kWh} / \mathrm{d}]$. Using the values found for constant load, prediction results are scaled down to the same mean value. The resulting battery sizes are compared in figure 2 with the results from Matlabcalculations with the algorithm from [11].

One difference between HOMER and Matlab results [11] is the allowed prediction error $P E$. In [11] a total error of $1 \%$ was permitted and the error was calculated referring to the battery throughput $Q_{B a t}$. In addition this error only was permitted for the battery power limit, for the energy curve in turn no error was assumed. Using the same algorithm from [11] battery sizes were recalculated for $\mathrm{PE}=1$ and $3 \%$ applied to both, power and energy limits. PE this time refers to total energy generation as it is the case in HOMER.

In the HOMER simulations only the unmet load percentage can be defined and was set in all simulations to $1 \%$. The excess energy in consequence would be allowed to be up to $2 \%$. HOMER permits sometimes considerable excess power (far more than $2 \%$ ) which cannot be limited directly. The load which represents the power injection to the grid is the only parameter available to manipulate excess energy. If the mean load is scaled up, excess power decreases and battery size increases. If the load is increased too much, no feasible solutions can be found because demand becomes higher than generation. In the simulations, the AC-load was changed until a PE of $3 \%$ was reached. In case B this was not possible due to the limitation of the number of batteries.

The conclusion is that battery size is very sensible to the permitted prediction error PE (or the parameters "unmet load" and "excess energy") and results have to be seen always in relation to theses values. Another consequence is that for each prediction interval, the predicted mean power is different which in turn effects the system efficiency. This point is treated more in detail in the next section (Wind-PV-Battery System).

Results show that the strong seasonal variations in wind speed make a total compensation of generation fluctuations with batteries very expensive. In addition HOMER starts the simulations always with a full battery and a system is feasible even if at the end of the year the battery is empty. If the battery size is more than 100 times smaller than $E_{\text {total }}$ it does not matter, but in this case, the battery size reaches with 194 MWh (case A) almost $30 \%$ of the total generation. Here HOMER has a weak point.

In HOMER first a small battery (Surrette S460) with 460 Ah / 2V per unit was used because it seemed most similar to the $500 \mathrm{Ah} / 2 \mathrm{~V}$ battery in [11]. But because the maximum number of batteries is limited to around 30,000 units, the largest time intervals were not feasible. Then the largest battery available in HOMER (Hoppecke 24OPzS 3000) with 3000 Ah / 2V was selected and results showed significant differences. Due to the fact that battery parameters can vary greatly, simulations will do so too. In figure 2 and table III the two batteries are represented with bat1 (Surrette S460) and bat2 (Hoppecke 24OPzS 3000). To approach the performance of the battery used in the Matlab model of [11], in HOMER the round trip efficiency of bat 2 was reduced from 86 to $80 \%$. In figure 2 the large difference between bat1 and bat2 can be seen. This fact shows that the battery parameters (such as maximum power density) are very important and in consequence a comparison of two simulations only can be good, if exactly the same battery 
parameters are used. Further work is needed to introduce in the Matlab model commonly used A/Ah curves and so achieve comparability and flexibility.

Apart from the differences it is interesting to observe that HOMER as well as Matlab changes the slope at a prediction interval of about $2 \mathrm{~h}$. This is the point when in Matlab the battery size restricted changes from maximum power demand (below $2 \mathrm{~h}$ prediction interval) to maximum energy demand.

It is not clear why HOMER calculates a battery with 540 kWh energy capacity at 1 h-prediction interval. Expected was zero $\mathrm{kWh}$ because one hour is the time step of HOMER calculations and the hourly load curve corresponds to the hourly generation curve from HOMER results.

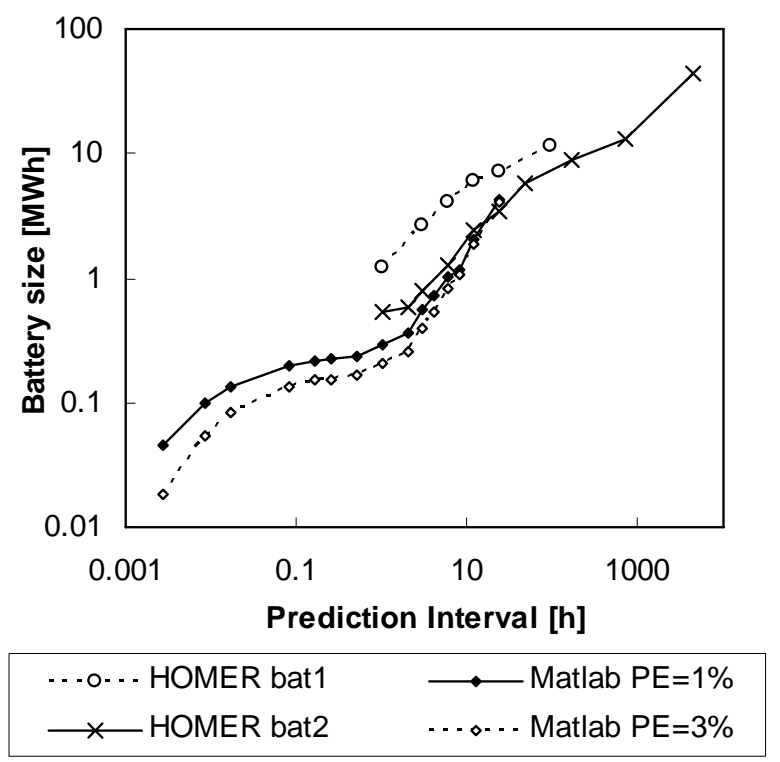

Fig. 2. Comparison of simulation results from HOMER and [11] (Matlab energy and power) at different prediction time intervals. HOMER bat1 (white circles) represents simulations with 460 Ah and HOMER bat2 (black circles) with 3000 Ah battery. All HOMER results have a prediction error of $3 \%$, Matlab results are presented for $\mathrm{PE}=1 \%$ (solid lines) and $\mathrm{PE}=$ $3 \%$ (dotted lines).

One difference between HOMER and Matlab results [4] is the allowed prediction error PE. It is defined as the loss of energy due to insufficient battery capacity relative to total energy generation. In the Matlab model, battery sizes were calculated for PE $=1$ and $3 \%$ in HOMER it is set to $3 \%$.

TABLE III. - Comparison of results from Matlab calculations according to [11] and HOMER simulations up to $24 \mathrm{~h}$.

\begin{tabular}{|c|c|c|c|c|c|}
\hline \multirow{2}{*}{$\begin{array}{c}\text { Pred. } \\
\text { interval } \\
\text { [h] }\end{array}$} & \multicolumn{3}{|c|}{ Battery capacity [kWh] } & \multicolumn{2}{|c|}{ Deviation [\%] } \\
\hline & $\begin{array}{l}\text { HOMER } \\
\text { bat2 }\end{array}$ & $\begin{array}{l}\text { Matlab } \\
\text { PE 3\% }\end{array}$ & $\begin{array}{l}\text { Matlab } \\
\text { PE 1\% }\end{array}$ & $\begin{array}{l}\text { Matlab } \\
\text { PE 3\% }\end{array}$ & $\begin{array}{l}\text { Matlab } \\
\text { PE 1\% }\end{array}$ \\
\hline 1 & 540 & 204 & 291 & -62.2 & -46.1 \\
\hline 2 & 594 & 251 & 366 & -57.7 & -38.4 \\
\hline 3 & 780 & 399 & 565 & -48.8 & -27.6 \\
\hline 6 & 1290 & 839 & 1008 & -35.0 & -21.9 \\
\hline 12 & 2460 & 1883 & 2035 & -23.5 & -17.3 \\
\hline 24 & 3480 & 4033 & 4294 & 15.9 & 23.4 \\
\hline
\end{tabular}

Battery size is very sensible to the permitted prediction error PE and results have to be seen always in relation to theses values. In HOMER two different batteries were used to show the importance of the battery model and its parameters.

\section{B. Wind $-P V-$ battery system}

It is expected that a hybrid Wind-PV-system is more favourable than a pure wind based generation, especially for low wind speed conditions, such as at Zaragoza airport. In figure 3 the calculated battery sizes for prediction time intervals up to 6 months are shown for 4 system configurations: wind only $(600 \mathrm{~kW}), \mathrm{PV}$ only (600 kW), wind $600 \mathrm{~kW}+$ PV $300 \mathrm{~kW}$ and wind $600 \mathrm{~kW}$ + PV $500 \mathrm{~kW}$. Wind power is not changed because it is assumed that only one wind generator with $600 \mathrm{~kW}$ is available.

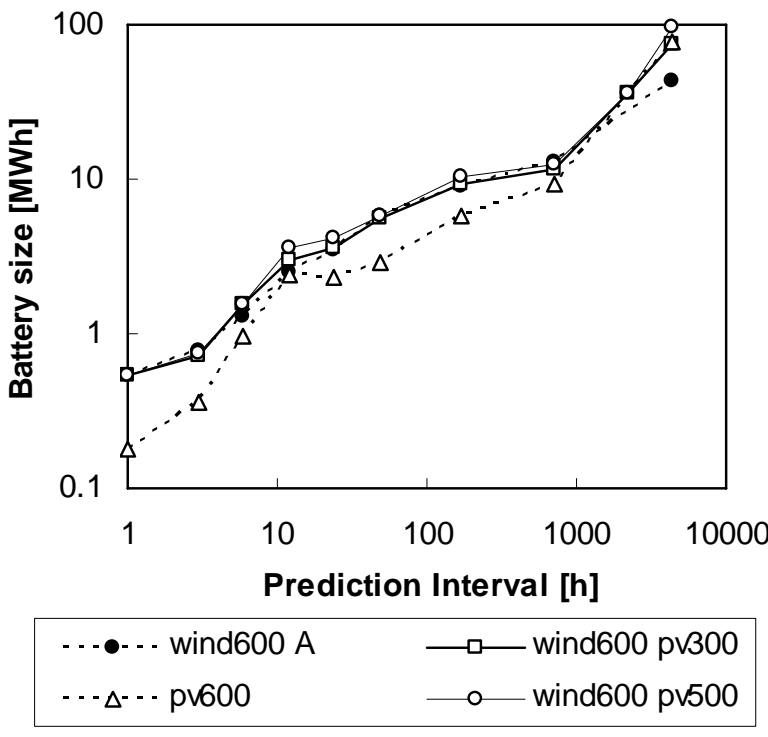

Fig. 3. Comparison of simulation results from Matlab and HOMER at different prediction time intervals.

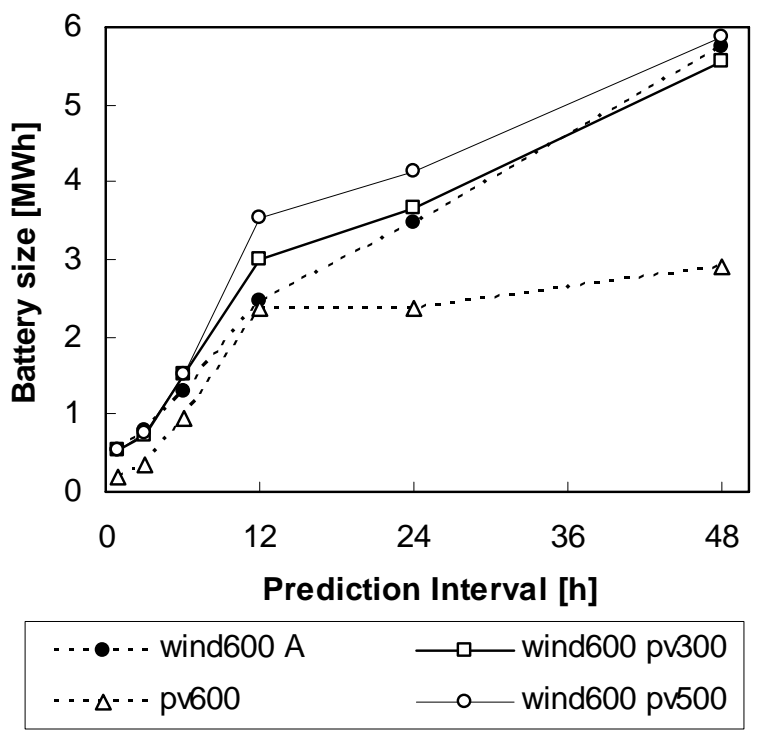

Fig. 4. HOMER results in linear scale for prediction time intervals from $1-48 \mathrm{~h}$. 
Figure 4 shows the results for $1-48$ h prediction interval in a linear scale for a better appreciation of the differences in battery size. In table IV the battery sizes are listed. For prediction intervals up to $48 \mathrm{~h}$, it becomes very clear that the pure PV system need far less battery capacity - around the half of a wind system with the same installed power. At the other hand, the hybrid systems do not need significantly more storage capacity than the pure wind - battery configuration. This is surprising because the system size almost doubles in the case of $500 \mathrm{~kW}$ installed PV peak power.

TABLE IV. - Battery sizes calculated by HOMER for the 4 system configurations for prediction time intervals up to $48 \mathrm{~h}$.

\begin{tabular}{|c|c|c|c|c|}
\hline \multirow{2}{*}{$\begin{array}{c}\text { Pred. } \\
\text { interval } \\
\text { [h] }\end{array}$} & \multicolumn{4}{|c|}{ Battery capacity [MWh] } \\
\hline & $\begin{array}{c}\text { wind } 600 \\
\mathrm{~A}\end{array}$ & $\begin{array}{c}\text { wind } 600 \\
\text { pv300 }\end{array}$ & $\begin{array}{c}\text { wind600 } \\
\text { pv500 }\end{array}$ & pv600 \\
\hline 1 & 0.540 & 0.540 & 0.540 & 0.180 \\
\hline 3 & 0.780 & 0.720 & 0.750 & 0.360 \\
\hline 6 & 1.290 & 1.530 & 1.530 & 0.960 \\
\hline 12 & 2.460 & 3.000 & 3.540 & 2.376 \\
\hline 24 & 3.480 & 3.660 & 4.140 & 2.358 \\
\hline 48 & 5.760 & 5.550 & 5.880 & 2.910 \\
\hline
\end{tabular}

Photovoltaics with $4000 \$ / \mathrm{kW}$ installed peak power is by a factor 4 more expensive than wind power (1000 \$/kW). At the other hand, the hybrid system need far less battery capacity per generated energy unit. Therefore it is not easy to estimate, if the hybrid system will be more cost effective. In the next paragraphs system efficiency and cost efficiency in terms of COE is compared for the 4 system configurations.

\section{B.1. Hybrid system efficiency}

At first the system efficiency is evaluated for the different configurations. As it was mentioned in the paragraphs above, system efficiency depends on battery throughput which in turn depends on the prediction interval. Battery throughput is almost proportional until $10 \mathrm{~h}$ prediction interval and then saturates as illustrated in figure 5 . While battery size for the pure wind system was almost equal to the hybrid configurations, the absolute throughput $Q_{B a t}$ is clearly the lowest of all cases. This is due to the low total energy production and the less regularly battery cycles. This means that occasional peaks define the battery size while solar systems generate daily peaks. In general it can be stated that a higher overall installed power and energy generation results in higher absolute battery throughput. To eliminate this effect, in figure 6 the relative battery throughput $q_{B a t}$ is depicted. Here some relations change dramatically. While in terms of absolute battery throughput the hybrid systems were had the highest values due to their greater installed power, now they are the lowest. The pure systems - wind and PV - show higher throughput rates than the hybrid systems relative to the overall generated power.
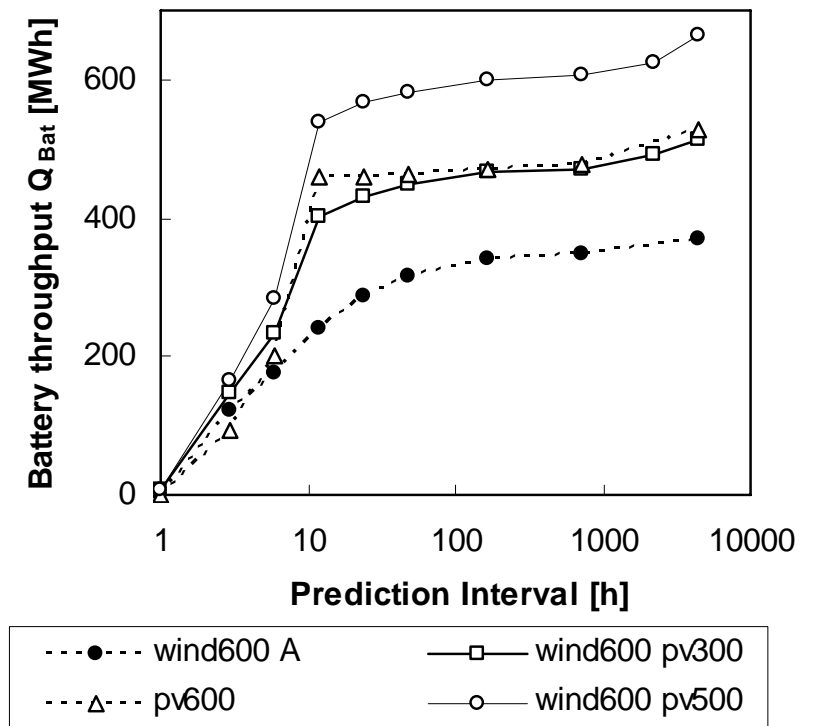

Fig. 5. Relation between the prediction interval and battery throughput $Q_{\text {Bat }}$.

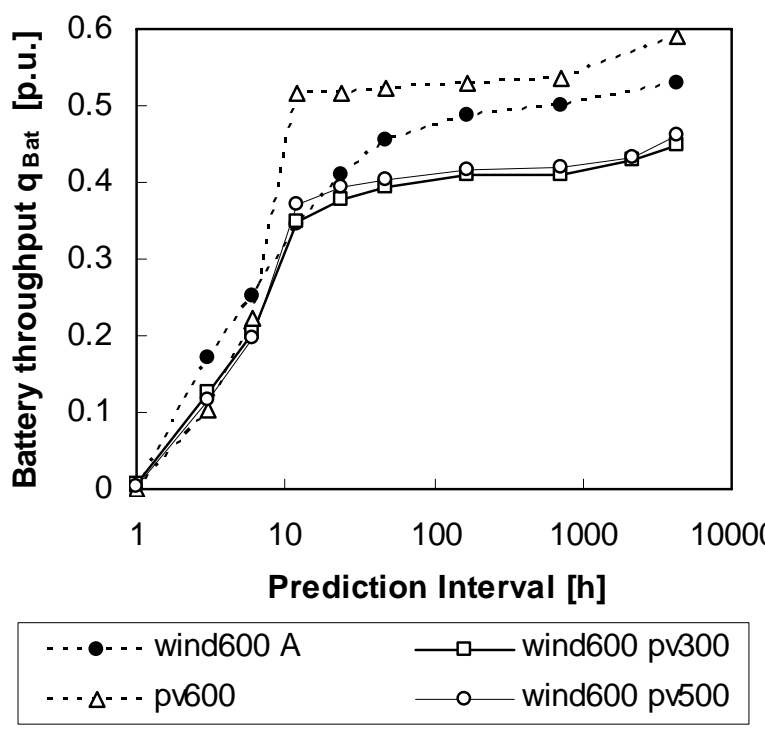

Fig. 6. Relation between the prediction interval and battery relative throughput $q_{\text {Bat }}$ (relative to total generated energy).

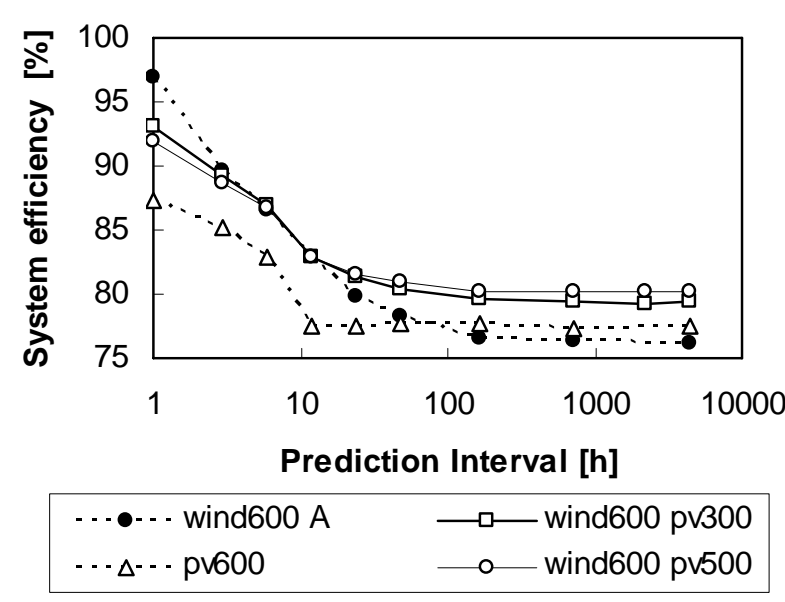

Fig. 7. Relation between the prediction interval and system efficiency $S L F$. 
In figure 7 , overall system efficiency is shown in relation to prediction interval length. The system efficiency can be set equal to the storage loss factor SLF although PV power always passes through the converter while wind power only passes the DC-branch if it have to be stored. Therefore at shorter prediction intervals, the pure PV-system is less efficient than the pure wind system. The hybrid configurations are best for prediction intervals over $12 \mathrm{~h}$.

\section{B.2. Hybrid system cost efficiency}

In the last paragraph it was shown that the hybrid configurations yield higher overall system efficiencies as systems with only one energy source. In this paragraph cost efficiency is evaluated. The cost of energy (COE) in HOMER represents the cost per kWh over the system lifetime. In our case 25 years are assumed. Battery lifetime depends on the throughput rate and can vary between 10 and 20 years. Battery replacement is reflected in the cost of energy. In figure $8 \mathrm{COE}$ is shown for systems with prediction up to 30 days. For larger intervals the cost grows significantly more so only this range is illustrated. In table $\mathrm{V}$ the numerical values are given including the prediction time interval of half a year.

As a general result it can be stated that the hybrid systems generate energy at a similar cost as the pure wind-battery system up to $12 \mathrm{~h}$. For larger prediction intervals the solar-wind combinations have a lower COE. While the pure solar-battery system is the most expensive up to $24 \mathrm{~h}$ prediction interval, it wins against pure wind for larger intervals. Comparing the two hybrid systems higher solar power results in lower energy cost for prediction intervals of $12 \mathrm{~h}$ and longer. The $600 \mathrm{~kW}$ Wind-battery-system with best wind conditions (wind600 $\mathrm{B}, 5.7 \mathrm{~m} / \mathrm{s}$ ) has been put in figure 8 to illustrate the impact of the quality of renewable resource on the energy price. The hybrid systems are calculated with the lower wind speed.

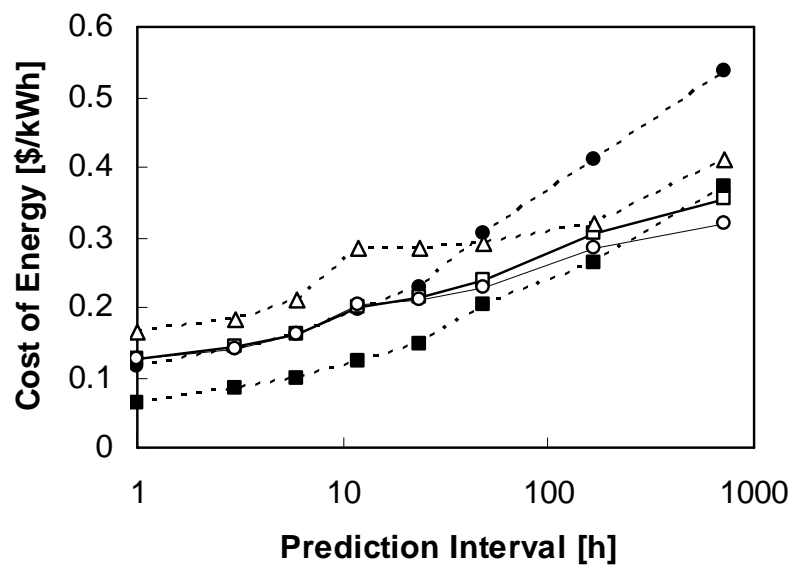

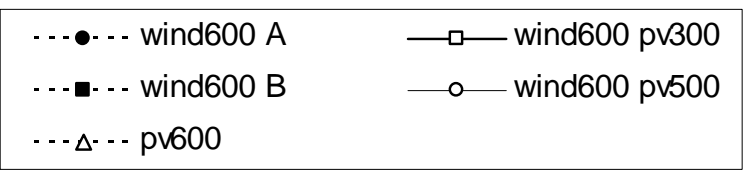

Fig. 8. Cost of energy (COE) depending on the prediction interval ranging from $1 \mathrm{~h}$ up to 30 days $(720 \mathrm{~h})$.
TABLE V. - Cost of energy (COE) calculated by HOMER for the 4 system configurations for prediction time intervals up to half a year.

\begin{tabular}{cccccc}
\hline \multirow{2}{*}{$\begin{array}{c}\text { pred. } \\
\text { interval } \\
\text { [h] }\end{array}$} & \multicolumn{5}{c}{ Cost of Energy (COE) [\$/kWh] } \\
\cline { 2 - 6 } & A & B & $\begin{array}{c}\text { wind600 } \\
\text { pv300 }\end{array}$ & $\begin{array}{c}\text { wind600 } \\
\text { pv500 }\end{array}$ & $\begin{array}{c}\text { pv60 } \\
\text { 0 }\end{array}$ \\
\hline 1 & 0.115 & 0.063 & 0.125 & 0.125 & 0.166 \\
3 & 0.141 & 0.084 & 0.143 & 0.141 & 0.184 \\
6 & 0.162 & 0.100 & 0.162 & 0.160 & 0.211 \\
12 & 0.198 & 0.123 & 0.201 & 0.204 & 0.285 \\
\hline 24 & 0.229 & 0.147 & 0.215 & 0.212 & 0.285 \\
48 & 0.304 & 0.205 & 0.237 & 0.227 & 0.291 \\
168 & 0.410 & 0.262 & 0.307 & 0.284 & 0.320 \\
720 & 0.537 & 0.372 & 0.353 & 0.319 & 0.410 \\
4380 & 1.432 & 1.006 & 1.472 & 1.472 & 1.967 \\
\hline $168 \mathrm{~h}=7$ days; $720 \mathrm{~h}=30$ days; $4380 \mathrm{~h}=$ half a year
\end{tabular}

A sensitivity study has been carried out to investigate more in detail the impact of the solar portion in the generation mix. For $48 \mathrm{~h}$ prediction interval and $600 \mathrm{~kW}$ wind power (low wind conditions, case A), solar power has been varied up to $1000 \mathrm{~kW}$. The result was a falling COE with rising solar power. This is not surprising because the pure PV-battery system has a slightly lower $\mathrm{COE}$ as the pure wind-battery system at $48 \mathrm{~h}$ prediction interval. Figure 9 shows the relation between installed solar power and COE.

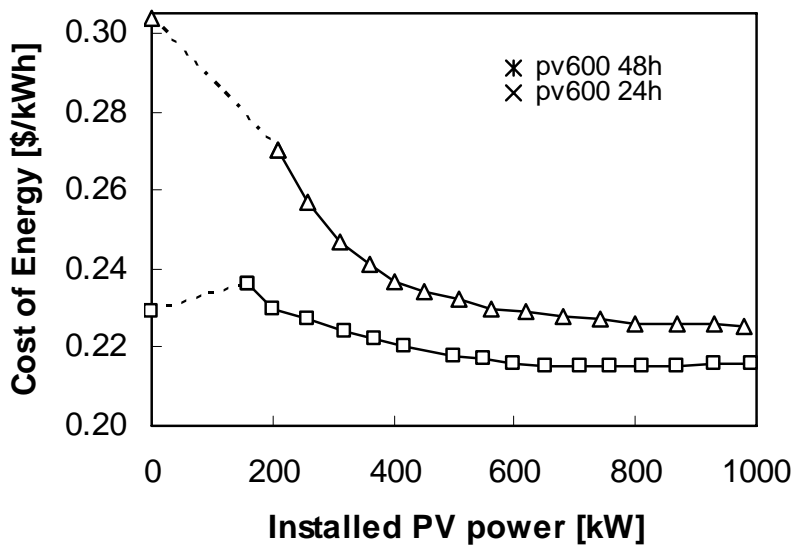

$\neg-$ Pred. Interv. 24h

$\neg-$ Pred. Interv. 48h

Fig. 9. Cost of energy (COE) depending on the solar power in a solar-wind hybrid system for prediction intervals of 12 and 24 h. At PV power $0 \mathrm{~kW}$ the COE for the wind600 system is shown and the asterisk/cross show COE of the pure PV system with $600 \mathrm{~kW}$ (pv600).

The conclusion from figure 9 is that wind-solar hybrid systems always are beneficial under the meteorological conditions in Zaragoza. Even if the pure solar system would be more costly (as with prediction interval $24 \mathrm{~h}$ ) an optimum combination can be found which has a COE below the systems with just one renewable source. 


\section{Wind $-P V-$ fuel cell system}

In battery storage systems as proposed here, often the battery sizes is defined by energy peaks. Especially in wind generation the result are very large batteries when the predictions interval grows. To minimize the battery size, HOMER proposes a quite large excess energy generation. On the other hand battery discharge is always possible at higher power than charge. But the proposed system results in a symmetric power demand (charge and discharge peaks of the same magnitude occur with the same statistical probability, see [11]). Therefore an intelligent use of excess energy would reduce the battery size and improve the system efficiency. One option could be the generation of hydrogen for fuel cell vehicles or domestic use.

\section{Conclusion}

Two battery sizing methods for grid-connected renewable energy systems with generation prediction have been compared. Differences are observed which can be explained by different battery model and time resolution. The Matlab model is focussed on the battery while HOMER simulates the hybrid system including a cost optimization. The main result is that PV-wind hybrid systems represent a better solution in terms of efficiency and energy cost compared with pure PV or wind systems with battery storage, given the meteorological conditions in Zaragoza. Simulation results are very sensitive to the power prediction method, the renewable resources and wind turbine power curve. Battery size reduces dramatically if more excess energy or unmet load is permitted. Therefore an intelligent use of excess energy would improve the system efficiency. One option could be the generation of hydrogen for fuel cell vehicles or domestic use.

\section{References}

[1] Red Eléctrica Española (REE), “Condiciones técnicas aplicables a la generación de régimen especial no gestionable", technical conditions for renewable energy production, reference: DDR.E/03/536. EDIC.: 4.
[2] P.G. Pligoropoulos, E.K. Bakis, A. Engler, M. Vandenbergh, P. Strauss, "Wind diesel battery systems for the Greek islands Sifnos, Serifos and Astipalea”, 2nd European PV-Hybrid and Mini-Grid Conference, 2003.

[3] N. Duic, L.M. Alves, $\mathrm{M}^{\mathrm{a}}$ da Graça Carvalho “Optimising the integration of hydrogen usage with intermittent energy sources”, Instituto Superior Técnico, Lisbon, Portugal, 2002

[4] http://www.insula.org/elhierro100.htm, "El Hierro -

[5] $100 \%$ Renewable Energy Island”, visited on june 24th 2005

[6] M.T. Iqbal, "A feasibility study of a zero energy home in Newfoundland”, Renewable Energy 29, 277-289, 2004.

[7] M.J. Khan, M.T. Iqbal, "Pre-feasibility study of standalone hybrid energy systems for applications in Newfoundland”, Renewable Energy 30, 835-854, 2005.

[8] D.J. Lew et al., "Hybrid wind/photovoltaic systems for households in Inner Mongolia”, Int. Conf. on Village Electrification through Renewable Energy, New Delhi, 35 March 1997.

[9] A. Frankel, "A cost efficiency analysis of energy options for the Dow Wetlands classroom", Report from College of Natural Resources at University of California at Berkeley, 2004; web site visited on june 29th 2005:

[10] http://ist-socrates.berkeley.edu/ es196/projects/2004final/.

[11] J.A. Puicercús et al. “Atlas eólico de Aragón”,

[12] ISBN: 84-7753-513-2; published by the government of Aragón1994.

[13] J.A. Turégano et al. “Atlas de radiación solar en Aragón”, published by the government of Aragón 1995.

[14] H. Bludszuweit et. al, "Simulation of a hybrid system Wind Turbine - Battery - Ultracapacitor", Int. Conf. on Renewable Energy and Power Quality ICREPQ’05, 2005.

[15] http://www.windpower.org/en/tour/wres/pwr.htm

[16] Typical Danish 600 kW wind turbine (last visited: jul 2005)

[17] http://www.hoppecke.com - Hoppecke home page (last visited: jul - 2005) 